\title{
Bimetallic zeolite imidazolate framework for enhanced lithium storage boosted by the redox participation of nitrogen atoms
}

\author{
Xiaobing Lou, Yanqun Ning, Chao Li, Xiaoshi $\mathrm{Hu}$, Ming Shen and Bingwen $\mathrm{Hu}^{*}$
}

\begin{abstract}
In this work, a bimetallic zeolitic imidazolate framework (ZIF) CoZn-ZIF was synthesized via a facile solvothermal approach and applied in lithium-ion batteries. The as-prepared CoZn-ZIF shows a high reversible capacity of $605.8 \mathrm{~mA} \mathrm{~h} \mathrm{~g}^{-1}$ at a current density of $100 \mathrm{~mA} \mathrm{~g}^{-1}$, far beyond the performance of the corresponding monometallic Co-ZIF67 and Zn-ZIF-8. Ex-situ synchrotron soft X-ray absorption spectroscopy, $\mathrm{X}$-ray diffraction, and electron paramagnetic resonance techniques were employed to explore the $\mathrm{Li}$-storage mechanism. The superior performance of CoZn-ZIF over CoZIF-67 and Zn-ZIF-8 could be mainly attributed to lithiation and delithiation of nitrogen atoms, accompanied by the breakage and recoordination of metal nitrogen bond. Morever, a few metal nitrogen bonds without recoordination will lead to the amorphization of CoZn-ZIF and the formation of few nitrogen radicals.
\end{abstract}

Keywords: bimetallic, zeolitic imidazolate framework, lithiumion battery, improved capacity, mechanism study

\section{INTRODUCTION}

With high energy density, shape versatility and light weight, rechargeable lithium-ion batteries (LIBs) are now becoming the most widely used energy storage and conversion devices for electric vehicles (EVs) and portable electronics [1]. Because the commercial anode graphite could only deliver a relatively low theoretical capacity of $372 \mathrm{~mA} \mathrm{~h} \mathrm{~g}^{-1}$, the development of new type anode materials with high capacity is one of the most important tasks in improving the performance of future LIBs [2]. Metal-organic frameworks (MOFs) including zeolitic imidazolate frameworks (ZIFs) with tunable metal centers and organic linkers are designed to meet various demands, including gas storage and separation, sensing, catalysis and drug delivery [3-6]. Recently, conjugated carboxylates based MOFs, such as Co-BDC $[7,8], \mathrm{Mn}$ BDC [9], Fe-BDC [10,11], Mn-BTC [12], CoBTC [13], $\mathrm{Cu}-\mathrm{BTC}$ [14] and Fe-BTC [15], are being employed in LIBs and have attracted tremendous attention for their high performances. Further researches indicate that lithium is inserted into organic moiety in these MOFs and it is deduced that the electron withdrawing effect of the conjugated carboxylates should be the main impetus in storing lithium-ions [12-19]. However, MOFs-based electrodes with other kinds of organic linkers are seldom employed in LIBs for the lack of highly-active lithiation sites. Regarding to ZIFs, although they have been intensively used as sacrificial templates or cladding materials to develop carbon [20,21], $\mathrm{ZnO}$ [22], $\mathrm{Sn} / \mathrm{C}$ [23] or thin film [24] for LIBs, their direct application as highperformance lithium storage electrode materials is still challenging. Tang et al. [25] recently reported the use of thin-film ZIF-8 and ZIF-67 electrodes as anodes for LIBs. With Li-ions insertion into the MOFs pores, reversible capacities of 335.3 and $311.6 \mathrm{~mA} \mathrm{~h} \mathrm{~g}^{-1}$ were maintained at a current density of $0.2 \mathrm{C}$, respectively. Another meaningful attempt was given by Chen et al [26]. Bifunctionalized MOFs (BMOFs) $\mathrm{Zn}(\mathrm{IM})_{1.5}(\mathrm{abIM})_{0.5} \quad$ (IM = imidazole, abIM $=2$-aminobenzimidazole) with both hydrophobic and polar functionalities were constructed by the reaction of IM, abIM, and zinc nitrate hexahydrate in $\mathrm{N}, \mathrm{N}$-dimethylformamide (DMF) solution. When tested as anode in the potential window of $0.01-3.0 \mathrm{~V} v s . \mathrm{Li} / \mathrm{Li}^{+}$, the as-prepared BMOFs showed a stable reversible capacity of approximate $190 \mathrm{~mA} \mathrm{~h} \mathrm{~g}^{-1}$ at a current density of $100 \mathrm{~mA} \mathrm{~g}^{-1}$ via the adsorption of Li-ions into IM group. Unfortunately, such capacities are still lower than the theoretical capacity of graphite.

State Key Laboratory of Precision Spectroscopy, Shanghai Key Laboratory of Magnetic Resonance, Institute of Functional Materials, School of Physics and Materials Science, East China Normal University, Shanghai 200062, China

* Corresponding author (email: bwhu@phy.ecnu.edu.cn) 
To improve the performance of ZIFs as anode materials for LIBs, we focus our attention on bimetallic ZIF to utilize the synergistic effect of two metal centers inspired by our previous work [16,27-29]. To demonstrate the effectiveness of our bimetallic ZIF, we also synthesize the isostructural Zn-ZIF-8 and Co-ZIF-67 under a similar solvothermal approach by using 2-methylimidazole as the linker. The electrochemical performances of Zn-ZIF-8, Co-ZIF-67, and CoZn-ZIF were investigated and compared. CoZn-ZIF shows a reversible capacity of $605.8 \mathrm{~mA} \mathrm{~h} \mathrm{~g}^{-1}$, which is more than 6 times that of $\mathrm{Zn}$ ZIF-8 (94.8 $\mathrm{mA} \mathrm{h} \mathrm{g}^{-1}$ ), and about 5 times that of Co-ZIF$67\left(122.0 \mathrm{~mA} \mathrm{~h} \mathrm{~g}^{-1}\right)$. To the best of our knowledge, the performance of our CoZn-ZIF is the best one in ever reported ZIFs. Furthermore, a series of ex-situ tests were also performed to explore the lithiation/delithiation mechanism. For the synergistic effect of the two metals, the nitrogen atoms are all involved in the Li-storage processes, leading to high reversible capacity accompanying with the collapse of long range order.

\section{EXPERIMENTAL SECTION}

\section{Synthetic methods of CoZn-ZIF, Zn-ZIF-8 and Co-ZIF-67} All chemicals and solvents were of analytical grade and were used without any further purification. The synthesis of the sample was performed following a convenient hydrothermal method. Typically, $\mathrm{Co}\left(\mathrm{NO}_{3}\right)_{2} \cdot 6 \mathrm{H}_{2} \mathrm{O}$ $(1.4512 \mathrm{~g}), \mathrm{Zn}\left(\mathrm{NO}_{3}\right)_{2} \cdot 6 \mathrm{H}_{2} \mathrm{O}(0.7493 \mathrm{~g})$ and 2-methylimidazole $(2-\mathrm{Im})(0.6148 \mathrm{~g})$ were respectively dissolved in 60 mL DMF and absolute methanol solvent $(5: 1, v / v)$ to form a clear solution under magnetic stirring. Subsequently, the solution was poured into a $100 \mathrm{~mL}$ Teflon-lined stainless steel autoclave after completely mixing. After heated at $150^{\circ} \mathrm{C}$ in an oven for $24 \mathrm{~h}$, the autoclave was spontaneously cooled down to room temperature in the fume hood. The resultant purple production was collected by pumping filtration. Eventually, the final powder designated as CoZn-ZIF was obtained after being dried under vacuum at $110^{\circ} \mathrm{C}$ for $12 \mathrm{~h}$. Similarly, for the synthesis of Zn-ZIF-8 and Co-ZIF-67, the procedures were carried out in the absence of $\mathrm{Co}\left(\mathrm{NO}_{3}\right)_{2} \cdot 6 \mathrm{H}_{2} \mathrm{O}$ or $\mathrm{Zn}\left(\mathrm{NO}_{3}\right)_{2} \cdot 6 \mathrm{H}_{2} \mathrm{O}$, respectively.

\section{Materials characterization}

A Nexus670 infrared spectrometer (Nicolet) was used to perform Fourier transform infrared spectroscopy (FTIR) analysis in the wavenumber range of $4,000-400 \mathrm{~cm}^{-1}$ in transmission mode. A Rigaku Ultima IV X-ray diffractometer $(\mathrm{XRD})$ with $\mathrm{Cu}-\mathrm{K}_{\alpha}$ radiation $(V=35 \mathrm{kV}, I=$
$25 \mathrm{~mA}, \lambda=1.5418 \AA$ ) was used to analyze the crystal phase of the as-prepared materials in the $2 \theta$ range of $5^{\circ}-50^{\circ}$ at a scanning rate of $20^{\circ} \mathrm{min}^{-1}$. TG curves that range from room temperature to $800^{\circ} \mathrm{C}$ was recorded on a STA 449 F3 Jupiter ${ }^{\circledast}$ simultaneous thermo-analyzer (NETZSCH Gerätebau $\mathrm{GmbH}$ ) at a heating rate of $10^{\circ} \mathrm{C} \mathrm{m^{-1 }}$ under air atmosphere. Scanning electron microscopy (SEM) images and energy dispersive X-ray spectroscopy (EDX) analyses were taken by a Hitachi S2400 scanning electron microscope (Japan). For an inductively coupled plasma (ICP) test, the sample was dissolved in $50 \mathrm{~mL}$ aqua-regia solution and then diluted to the proper concentration (100 times or more) with water to measure the amount of $\mathrm{Co}$ and $\mathrm{Zn}$ using a Varian 720-ES ICP/OES. X-ray photoelectron spectroscopy (XPS) tests were recorded on a ThermoFisher Scientific ESCALAB 250Xi spectrometer operating at $250 \mathrm{~W}\left(\mathrm{Al}-\mathrm{K}_{\alpha}\right.$ radiation $=1,486.6 \mathrm{eV}$, pass energy $=$ $93.9 \mathrm{eV})$. Synchrotron-based soft X-ray absorption spectroscopy (sXAS) analyses were performed at the National Synchrotron Radiation Laboratory in Hefei, China. The N K-edge (395-410 eV) and Co L-edge (765-810 eV) were selected in measuring the total electron yield from the ZIFs with a resolution of $0.2 \mathrm{eV}$. Zn L-edge could not be measured due to the higher requirement for energy $(>1,000 \mathrm{eV})$. A Bruker Elexsys 580 spectrometer equipped with HS cavity was used to collect the electron paramagnetic resonance (EPR) spectra. Microwave power (4.743 mW), modulation amplitude (1 G), modulation frequency $(40 \mathrm{kHz})$, sweep time $(50 \mathrm{~s})$, conversion time $(12.21 \mathrm{~ms})$ and time constant $(40.96 \mathrm{~ms})$ were all reasonably set.

\section{Electrochemical testing}

All the electrochemical measurements were carried out at room temperature. The active material (weight ratio: $70 \%$ ), conducting additive (Super-P carbon black, weight ratio: 20\%) and the binder (polyacrylic acid (PAA), weight ratio: $10 \%)$ were homogenously mixed in $N$-methyl-2-pyrrolidone (NMP, solvent) and stirred for at least $3 \mathrm{~h}$ to produce a slurry. Then, the obtained slurry was coated onto $\mathrm{Cu}$ foil and dried at $110^{\circ} \mathrm{C}$ in vacuum oven for $12 \mathrm{~h}$. The electrodes were punched into round plates (diameter of $14.0 \mathrm{~mm}$ ). The loading of the as-prepared electrodes is about $\sim 1.2 \mathrm{mg} \mathrm{cm}^{-2}$. $1 \mathrm{~mol} \mathrm{~L}^{-1} \mathrm{LiPF}_{6}$ in ECDMC-EMC (1:1:1 in volume) was used as the electrolyte. Finally, a coin cell (CR2032) was assembled by the asprepared anode, a Celgard 2325 separator (diameter of $19.0 \mathrm{~mm}$ ), a pure lithium wafer (counter electrode and reference electrode), and electrolyte in an argon filled 

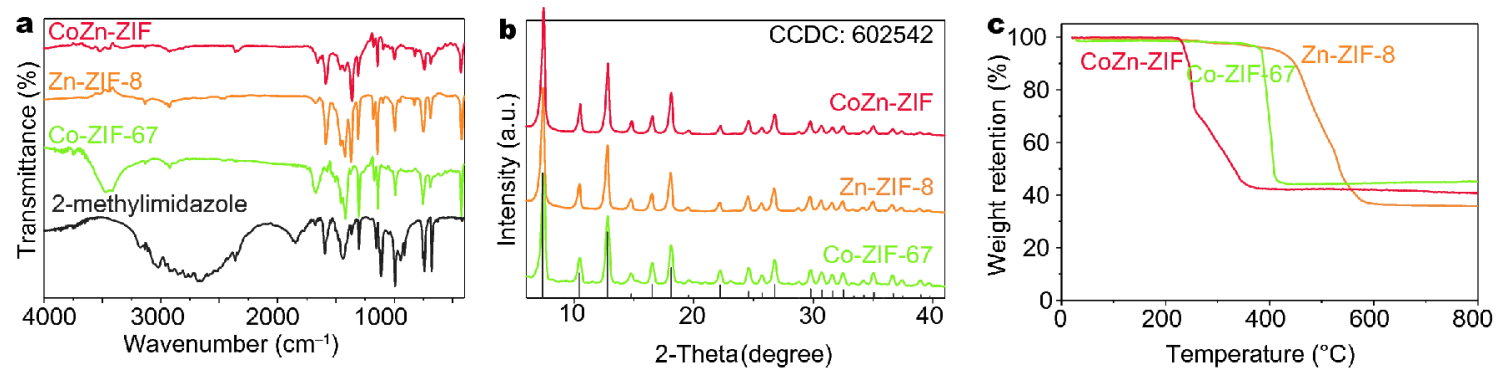

Figure 1 FTIR spectra (a), XRD patterns (b) and TG curves (c) of Zn-ZIF-8, Co-ZIF-67, and CoZn-ZIF, respectively. The FTIR spectrum of 2methylimidazole is also involved for reference.

glove box with oxygen and water less than $0.1 \mathrm{ppm}$. The galvanostatic charge and discharge and rate tests were performed on a LAND 2001A battery test system in the voltage range of $0.01-3 \mathrm{~V}$ versus $\mathrm{Li} / \mathrm{Li}^{+}$. Cyclic voltammetry $(\mathrm{CV})$ testing was carried out on an electrochemical workstation (CHI660e) at a scan rate of $0.2 \mathrm{mV} \mathrm{s}^{-1}$ in the voltage range of $0.01-3 \mathrm{~V}$ versus $\mathrm{Li} / \mathrm{Li}^{+}$. Electrochemical impedance spectra (EIS) measurements were recorded on an electrochemical workstation (CHI660e) in the frequency range of $0.01 \mathrm{~Hz}$ to $100 \mathrm{kHz}$ with alternating current (AC) amplitude of $5 \mathrm{mV}$.

\section{RESULTS AND DISCUSSION}

\section{Materials characterization}

FTIR spectra of 2-methylimidazole, Zn-ZIF-8, Co-ZIF-67 and CoZn-ZIF are shown in Fig. 1a. It can be observed that the characteristic bands $\left(1,846 \mathrm{~cm}^{-1}\right.$ : the resonance between the out of plane $\gamma_{\mathrm{N}-\mathrm{H} \cdots \mathrm{N}}$ and the $v_{\mathrm{N}-\mathrm{H}}$ proton stretching vibrations; $2,300-3,300 \mathrm{~cm}^{-1}$ : the presence of a $\mathrm{N}-\mathrm{H} \cdots \mathrm{N}$ hydrogen bond established between two 2-methylimidazole) of 2-methylimidazole disappear in the FTIR spectrum of the three ZIFs, indicating the deprotonation of 2-methylimidazole upon coordination with metals [30].

Powder XRD patterns of the three ZIFs are displayed in Fig. $1 \mathrm{~b}$ with the simulated sodalite-topology Zn-ZIF-8 patterns (CCDC No: 602542). Due to the comparable ionic radii of $\mathrm{Zn}^{2+}(0.74 \AA)$ and $\mathrm{Co}^{2+}(0.72 \AA)$ in tetrahedral coordination, $\mathrm{Co}^{2+}$ can substitute $\mathrm{Zn}^{2+}$ in the crystal of Zn-ZIF-8, generating isostructural CoZn-ZIF. The XRD patterns are identical for all samples and no additional phases can be found, demonstrating the isostructural nature of the three compounds. Moreover, sharp peaks were observed at $7.4^{\circ}(110), 12.8^{\circ}(211)$, and $18.1^{\circ}$ (222) for all the three ZIFs, indicating a high degree of crystallinity. The atomic ratio of $\mathrm{Co}$ and $\mathrm{Zn}$ in the as- prepared CoZn-ZIF was 64:36, as estimated by ICP optical emission spectrometry (ICP-OES, Table S1). The difference of the $\mathrm{Co} / \mathrm{Zn}$ ratio between reactants $(2: 1)$ and products (64:36) could be due to the different coordination ability of Co and $\mathrm{Zn}$.

The thermal gravimetric analysis (TGA) curves of these ZIFs are shown in Fig. 1c. The TGA curves show a plateau followed by significant weight loss due to thermal decomposition of ZIF structures. However, CoZn-ZIF (decomposed at about $250^{\circ} \mathrm{C}$ ) presented a lower stability than Zn-ZIF-8 and Co-ZIF-67, probably for its higher chemical activity inspired by the synergistic effect of the two metals.

Fig. 2 presents the SEM images of the three ZIFs. Large crystals $(\sim 1 \mu \mathrm{m})$ are formed under the hydrothermal process, which is similar to the previously reported samples [31,32]. The coexistence and homogeneous distribution of different elements in three ZIFs are proved in Fig. S1 and S2.

\section{Electrochemical performances}

The cycling behaviours of the ZIFs were firstly evaluated at $100 \mathrm{~mA} \mathrm{~g}^{-1}$ in the voltage range from 0.01 to $3.0 \mathrm{~V}$ versus $\mathrm{Li} / \mathrm{Li}^{+}$. As shown in Fig. 3a, CoZn-ZIF showed a high discharge capacity of $1,336.0 \mathrm{~mA} \mathrm{~h} \mathrm{~g}^{-1}$ and a charge capacity of $697.8 \mathrm{~mA} \mathrm{~h} \mathrm{~g}^{-1}$ at the first cycle with an initial coulombic efficiency (CE) of 52.23\%. A relatively low CE of CoZn-ZIF should be ascribed to the formation of solid electrolyte interface (SEI) film and other irreversible reactions [33]. A charge capacity of $636.3 \mathrm{~mA} \mathrm{~h} \mathrm{~g}^{-1}$ was obtained at the second cycle, which is stabilized at $605.8 \mathrm{~mA} \mathrm{~h} \mathrm{~g}^{-1}$ after 100 cycles with CE approaching $100 \%$. To our knowledge, this is the highest reversible $\mathrm{Li}^{+}$ storage capacity reported for ZIFs-based anodes (Table S2). In comparison, Zn-ZIF-8 and Co-ZIF-67 only deliver a discharge capacity of 206.2 and $268.8 \mathrm{~mA} \mathrm{~h} \mathrm{~g}^{-1}$, along with a coulombic efficiency of $39.19 \%$ and $50.09 \%$, re- 


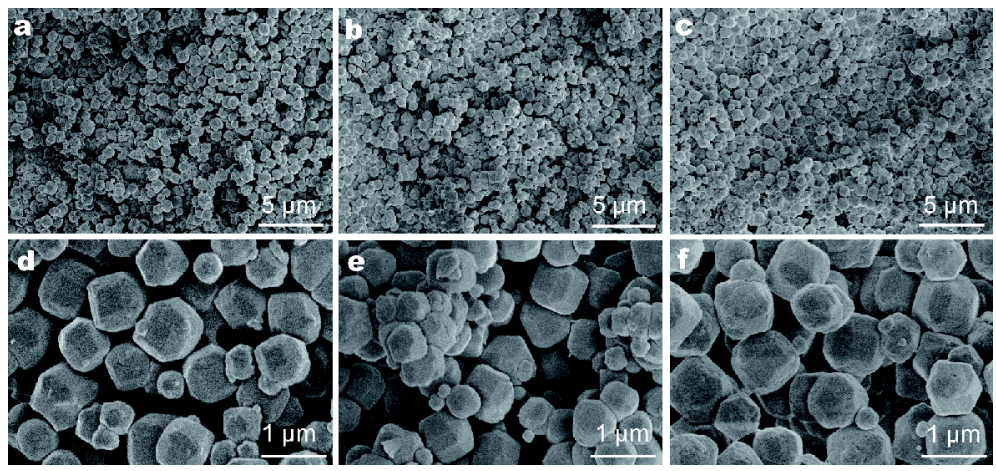

Figure 2 SEM micrographs of Zn-ZIF-8 (a, d), Co-ZIF-67 (b, e), and CoZn-ZIF (c, f) at different magnifications.
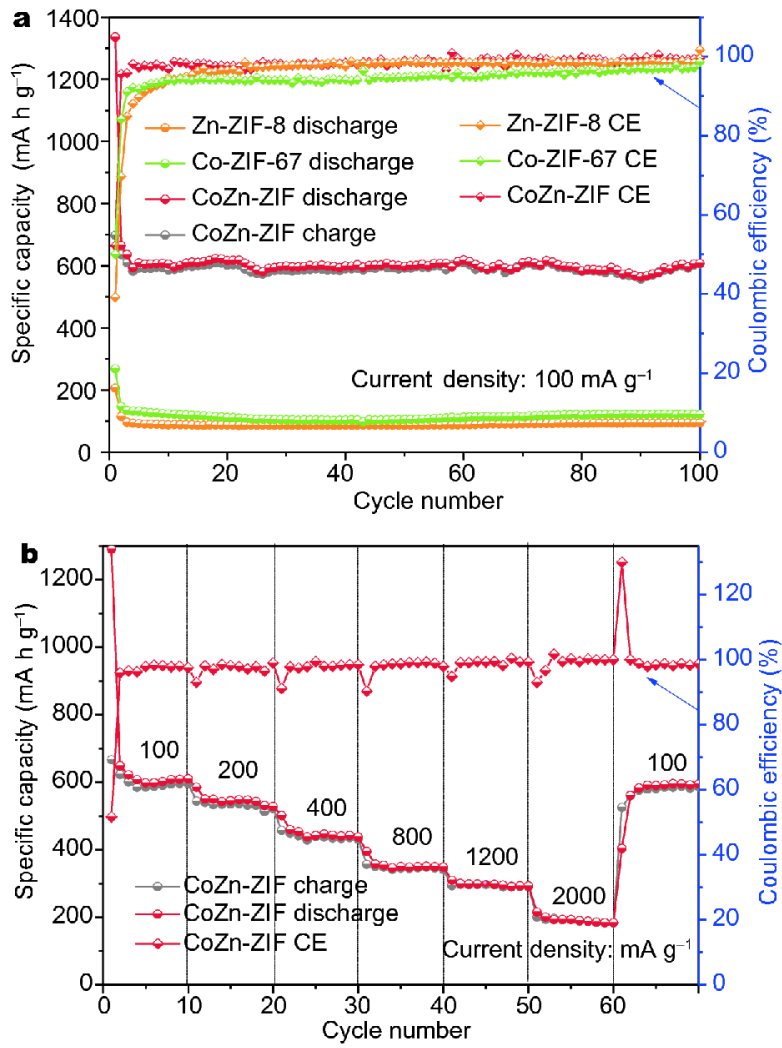

Figure 3 (a) Cyclic performance of CoZn-ZIF at a current density of $100 \mathrm{~mA} \mathrm{~g}^{-1}$. The discharge and coulombic efficiency curves of Zn-ZIF-8 and Co-ZIF-67 are also provided for comparison. (b) Rate performance of CoZn-ZIF at different current densities ranging from 100 to $2,000 \mathrm{~mA} \mathrm{~g}^{-1}$.

spectively at the first cycle. After 100 cycles, only $94.8 \mathrm{~mA} \mathrm{~h} \mathrm{~g}^{-1}$ and $122 \mathrm{~mA} \mathrm{~h} \mathrm{~g}^{-1}$ can be maintained for Zn-ZIF-8 and Co-ZIF-67, which is nearly $1 / 6$ and $1 / 5$ of CoZn-ZIF's capacity, respectively. The rate performance of CoZn-ZIF was also tested, as illustrated in Fig. 3b. The reversible capacities are $610.5,523.0,437.8,341.6,290.8$ and $183.7 \mathrm{~mA} \mathrm{~h} \mathrm{~g}^{-1}$ at $100,200,400,800,1,200$ and $2,000 \mathrm{~mA} \mathrm{~g}^{-1}$, respectively. After the high-current cycles, the capacity could recover to $586.9 \mathrm{~mA} \mathrm{~h} \mathrm{~g}^{-1}$ at a current of $100 \mathrm{~mA} \mathrm{~g}^{-1}$, indicating the excellent rate capability and electrochemical stability.

Other electrochemical characterizations are shown in ESI (Fig. S3-5). The CV curves of Zn-ZIF-8 show a weak cathodic peak at $0.75 \mathrm{~V}$ at the initial cycle for the formation of SEI films (Fig. S3a). Besides, no obvious peaks could be found and identical CV curves are observed after the initial cycle indicating an adsorption-lithiation behavior of Zn-ZIF-8. For Co-ZIF-67, after the initial cycle, there still exist several weak peaks (Fig. S4a) demonstrating the existence of side reactions in Co-ZIF-67 which may degrade the crystallinity of MOF and weaken the XRD peaks. As for CoZn-ZIF, two pairs of peaks can be observed (Fig. S5a) which can be attributed to the reduction/oxidation of $\mathrm{Co}^{2+}$ and lithiation/delithiation of nitrogen atoms during the discharge/charge. The CV curves are not coincident in the several initial cycles indicating the activation of electrode.

\section{Mechanism study}

On the basis of ZIF $\left(\mathrm{C}_{8} \mathrm{H}_{10} \mathrm{~N}_{4} \mathrm{M}\right.$, M: Co or $\left.\mathrm{Zn}\right)$ units, one mole $\mathrm{Li}$ insertion into per formula unit corresponds to a capacity of $\sim 120 \mathrm{~mA} \mathrm{~h} \mathrm{~g}^{-1}$ [25]. So the electrochemical process of Zn-ZIF-8, Co-ZIF-67 and CoZn-ZIF may be described as follows:

$$
\begin{aligned}
& \mathrm{Zn}(2-\mathrm{Im})_{2}+\mathrm{Li}^{+}+\mathrm{e}^{-} \rightleftharpoons \mathrm{Zn}(2-\mathrm{Im})_{2} \mathrm{Li}, \\
& \mathrm{Co}(2-\mathrm{Im})_{2}+\mathrm{Li}^{+}+\mathrm{e}^{-} \rightleftharpoons \mathrm{Co}(2-\mathrm{Im})_{2} \mathrm{Li}, \\
& \mathrm{Co}_{0.64} \mathrm{Zn}_{0.36}(2-\mathrm{Im})_{2}+5 \mathrm{Li}^{+}+5 \mathrm{e}^{-} \\
& \rightleftharpoons \mathrm{Co}_{0.64} \mathrm{Zn}_{0.36}(2-\mathrm{Im})_{2} \mathrm{Li}_{5} .
\end{aligned}
$$

It should be mentioned that the previous reported ZIF 

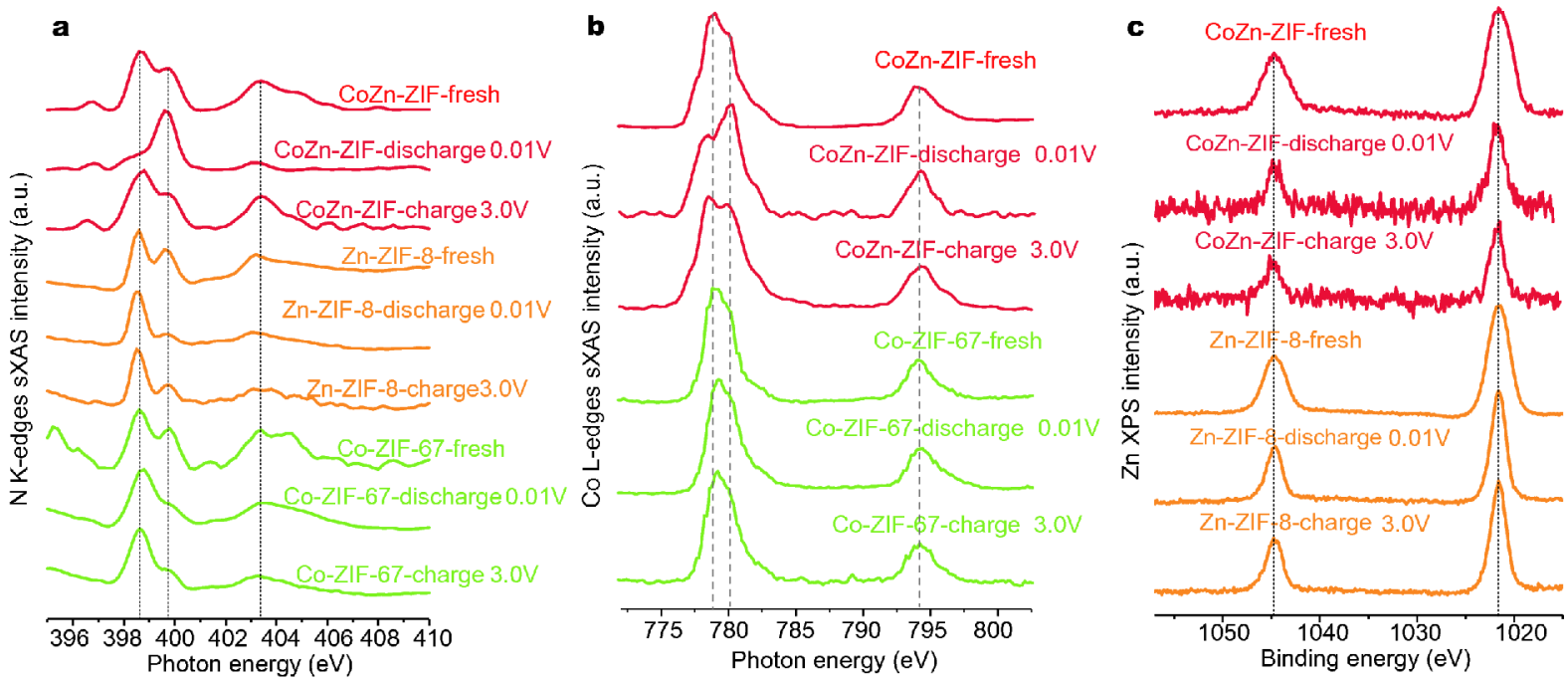

Figure 4 Ex situ N K-edges (a) and Co L-edges (b) sXAS spectra of the corresponding ZIF electrodes at different states-of-charge. (c) High-resolution $\mathrm{Zn} 2 \mathrm{p}$ XPS spectra of the corresponding ZIF electrodes at different states-of-charge.

material is only able to react with one Li ion per formula, through the adsorption of one $\mathrm{Li}$ ion into the imidazole rings $[25,26]$. However, the CoZn-ZIF could absorb more than $4 \mathrm{Li}^{+}$. Considering that there are four $\mathrm{N}$ atoms in one unit, we propose that the $\mathrm{N}$ atoms might involve in the $\mathrm{Li}$ storage of CoZn-ZIF while they might not involve for ZnZIF-8 and Co-ZIF-67.

To prove the hypothesis, the cells were firstly discharged $(0.01 \mathrm{~V})$ or charged $(3.0 \mathrm{~V})$ to the desired statesof-charge (SOCs) at $100 \mathrm{~mA} \mathrm{~g}^{-1}$. Then the cells were disassembled and the electrodes were washed with dimethyl carbonate (DMC) for several times in an argon filled glove box with oxygen and water less than $0.1 \mathrm{ppm}$ before ex-situ tests.

Nitrogen K-edge sXAS spectra of the three ZIFs electrodes at fresh, discharged $(0.01 \mathrm{~V})$ and charged $(3.0 \mathrm{~V})$ states can be found in Fig. 4a. As there are no other $\mathrm{N}$ atoms in electrolyte or SEI, the ex-situ study on $\mathrm{N}$ atoms can fully reflect the evolution of ZIFs. In the case of fresh ZIFs electrodes, the peaks observed at $A_{1}(398.6 \mathrm{eV})$ can be attributed to the transition of nitrogen $(\mathrm{N}) 1 \mathrm{~s}$ electrons to antibonding nitrogen $2 \mathrm{p}$ orbitals hybridized with $\mathrm{M}$ ( $\mathrm{M}$ : Co or $\mathrm{Zn}$ ) $3 \mathrm{~d}$ orbitals. In contrast, the peak at $\mathrm{A}_{2}$ reveals a transition from $\mathrm{N} 1 \mathrm{~s}$ to a $\pi^{*}$ type orbital from the mixture of $\mathrm{N} 2 \mathrm{p}$ with $\mathrm{C} 2 \mathrm{p}$ orbital, both bonding and antibonding. A broad feature observed at $\mathrm{A}_{3}(403.4 \mathrm{eV})$ is associated with the transitions from $\mathrm{N}$ 1s to a $\pi^{*}$ type orbital mixing $\mathrm{N} 2 \mathrm{p}$ with $\mathrm{C} 2 \mathrm{p}$ orbital in antibonding fashion, together with some $\mathrm{N} 2 \mathrm{p}-\mathrm{M} 4 \mathrm{sp}$ contributions [34]. After discharged to $0.01 \mathrm{~V}$, the $A_{1}$ peak disappeared in CoZn-ZIF, indicating the weakening or breaking of $\mathrm{M}$ $\mathrm{N}$ (M: Co or Zn; $\mathrm{N}$ is nitrogen) coordination bond after the Li-ion insertion in the imidazole ring. After such process, the excited electrons from $\mathrm{N}$ 1s can only transit to $\pi^{*}$ orbit of $\mathrm{C}-\mathrm{N}-\mathrm{Li}$ in imidazole rings, resulting in the slight enhancement of $\mathrm{A}_{2}$ peak intensity. Moreover, after charging back to $3.0 \mathrm{~V}$, the $\mathrm{N} \mathrm{K}$-edge sXAS features of CoZn-ZIF recovered to nearly same to that of fresh state, indicating the re-hybridization of $\mathrm{N} 2 \mathrm{p}$ with $\mathrm{M} 3 \mathrm{~d}$ orbitals upon delithiation. Based on the above observations, it is reasonable to believe that $\mathrm{Li}$-ions are inserted into the coordinative $\mathrm{N}$ atoms, which would induce the dissociation of $\mathrm{Co}-\mathrm{N}$ or $\mathrm{Zn}-\mathrm{N}$ coordination bond. The dissociation of $\mathrm{Co}-\mathrm{N}$ or $\mathrm{Zn}-\mathrm{N}$ bond would lead to the collapse of the crystalline structure, which is confirmed by the powder XRD patterns of the CoZn-ZIF sample at fully-discharged state (Fig. 5c).

For comparison, the $\mathrm{N} \mathrm{K}$-edge sXAS features of $\mathrm{Zn}$ ZIF-8 and Co-ZIF-67 are also plotted. It can be observed that the $A_{1}$ peak remained unchanged while $A_{2}$ peak was attenuated for both samples. Furthermore, the PXRD spectra of Zn-ZIF-8 at fully-discharged state is almost the same to that of pristine Zn-ZIF-8 (Fig. 5a), which suggests that the $\mathrm{Li}^{+}$insertion in the imidazole group of Zn-ZIF-8 only leads to the weakening of $\mathrm{C}-\mathrm{N}$ bond while $\mathrm{Zn}-\mathrm{N}$ bonds remained unchanged. Similarly, the PXRD spectrum of Co-ZIF-67 at fully-discharged state shows the same peaks with fresh state (Fig. 5b), only with the slight attenuation of the peaks at $7.4^{\circ}(110)$ and $10.4^{\circ}(200)$, which suggests that the $\mathrm{Co}-\mathrm{N}$ bond in Co-ZIF-67 is also 

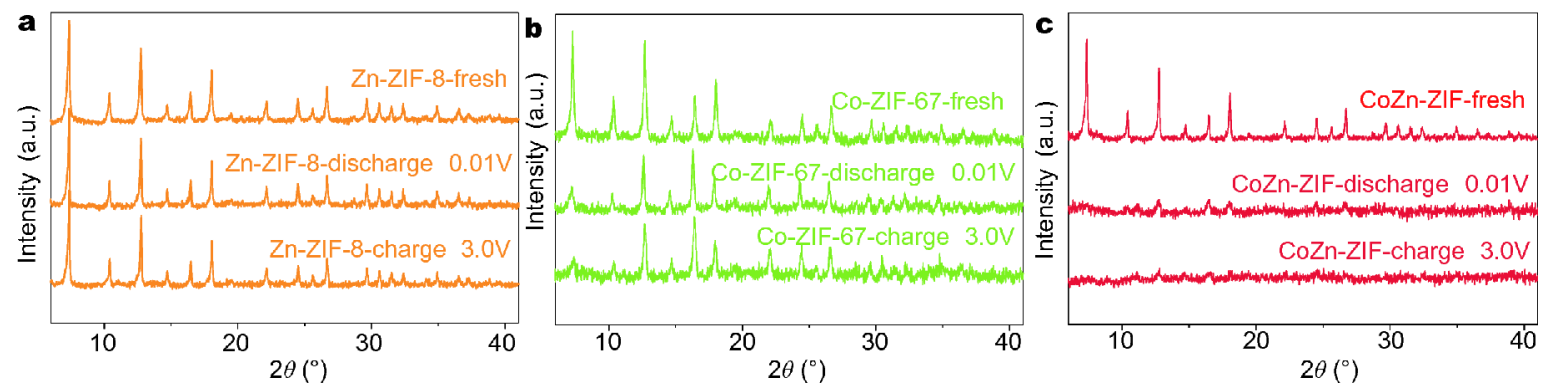

Figure 5 Ex-situ XRD patterns of fresh electrode, discharged electrode (0.01 V) and charged electrode (3.0 V) for (a) Zn-ZIF-8, (b) Co-ZIF-67 and (c) CoZn-ZIF.
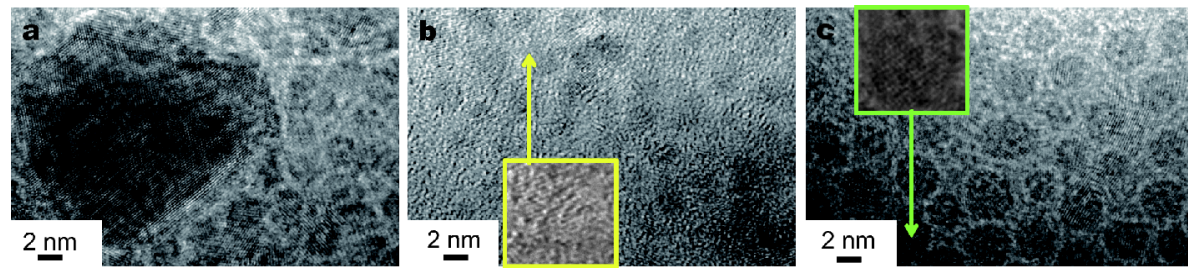

Figure 6 Microstructures evolutions (ex-situ TEM images) of fresh electrode, discharged electrode (0.01 V), and charged electrode (3.0 V) for CoZnZIF.

retained and weakened.

It is interesting to point out that these results can also be confirmed by Co L-edge sXAS and XPS spectra of CoZn-ZIF and Co-ZIF-67 (Fig. 4b and Fig. S6). Arising from the transitions of core electrons to outer empty orbitals, sXAS can offer the information about electronic states of transition-metals. Two regions can be observed around $779 \mathrm{eV}\left(\mathrm{L}_{3}\right.$ edge $)$ and $794 \mathrm{eV}\left(\mathrm{L}_{2}\right.$ edge $)$ and a double-peak feature can be distinguished in the $\mathrm{L}_{3}$-edge region. In the case of Co-ZIF-67, no discernible changes can be observed at the three desired states-of-charges, demonstrating the invariability of $\mathrm{Co}^{2+}$ and chemical environment. For Co L-edge sXAS features of CoZn-ZIF, significantly changes can be observed at $\mathrm{B}_{1}(778.8 \mathrm{eV})$ and $\mathrm{B}_{2}(780.1 \mathrm{eV})$, denoting the variation of local ligand environment. For XPS spectra, an obvious shift has been detected after discharge, demonstrating the reduction of $\mathrm{Co}^{2+}$. Moreover, the Co sXAS and XPS features of charged state are quite similar to that of pristine CoZn-ZIF, indicating the reversibility of the local ligand environment and valence of Co element upon cycling.

To further ascertain the $\mathrm{Zn}$-metal valence during cycles, ex-situ XPS spectra were plotted in Fig. 4c, which show that the $Z n$-metal valence remains unchanged for both Zn-ZIF-8 and CoZn-ZIF. These results suggest that in the case of CoZn-ZIF, the Co-N bond is broken while $\mathrm{Zn}-\mathrm{N}$ bond is kept during the discharging process, which leads to the amorphization of the CoZn-ZIF.

Ex-situ TEM (Fig. 6) was also employed for CoZn-ZIF to make it clear what happened to the ZIF structures. Large bulk crystal with well-defined lattice fringes could be clearly observed at the fresh CoZn-ZIF electrode. At the discharged state, only few vague lattice fringes could be distinguished indicating the destruction of large lattices accompanied by the disappearance of powder XRD patterns. After one cycle, with the re-coordination of Co$\mathrm{N}$ bonds, small lattices or nano-domains with a diameter of about $3 \mathrm{~nm}$ (Fig. 6c) are formed. But the diffraction peaks could not recover, for most of the nano-domains are smaller than the resolution limit of the XRD approximate $(3 \mathrm{~nm})$.

Ex-situ sXAS analyses disclose that the $\mathrm{Co}-\mathrm{N}$ bonds will reversibly break and regenerate for CoZn-ZIF. However, the ZIF structure would not automatically recrystallize in a higher scale proved by irreversible XRD and TEM at the charged states. We supposed that there might exist few coordination bonds which will not reversibly form upon charging. In such hypothesis, the delithiation of $\mathrm{N}-\mathrm{Li}$ without the formation of $\mathrm{Co}-\mathrm{N}$ ligand may give rise to nitrogen radicals in the uncoordinated $\mathrm{N}$, which has been proved by ex-situ EPR in Fig. 7. No signals can be detected in pristine ZIFs, but free electrons from Super-P conductive additives can generate an intense signal at $3510 \mathrm{G}(g=2.0013$, linewidth $=$ 


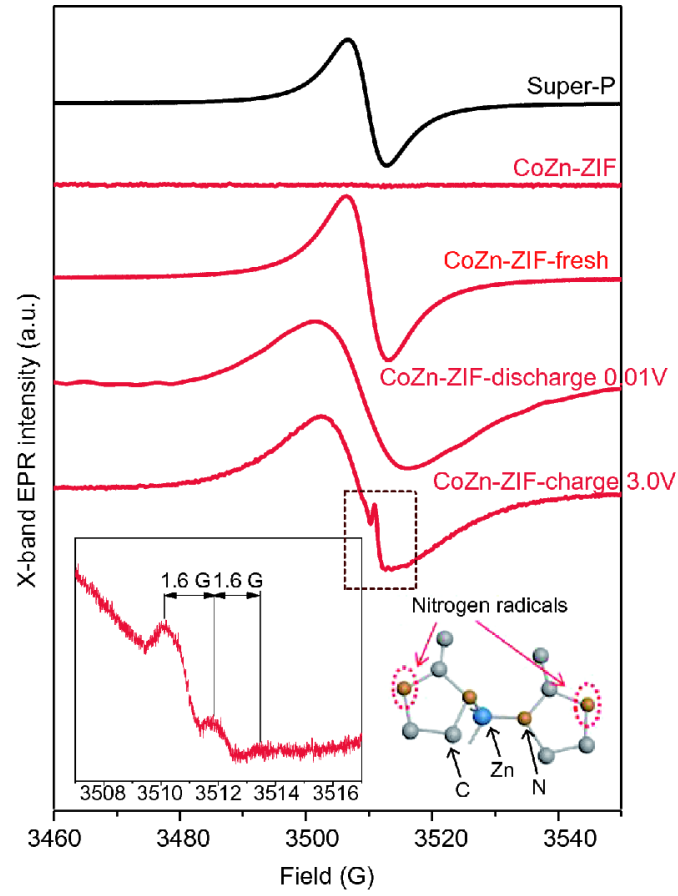

Figure 7 Ex situ EPR spectra of CoZn-ZIF electrodes at different statesof-charge. Pure Super-P and pristine CoZn-ZIFs are also plotted for comparison. Insert: high-resolution EPR spectrum from selected region and schematic illustration of nitrogen radicals. Other EPR spectra are displayed in Fig. S6. Here, CoZn-ZIF-fresh is the sample with Super-P while CoZn-ZIF is not.

6.2 G). Thus, this signal of Super-P can be observed for all electrodes. The most spectacular result is that a sharp signal with $g$-factor value of 2.0008 is observed only in the charged CoZn-ZIF electrodes, indicating the formation of radicals in such state. In a high-resolution EPR spectrum, triple splitting $(g=2.0008, A=1.6 \mathrm{G})$ is observed for charged CoZn-ZIF at 3,512 G, revealing the existence of nitrogen $(S=1)$ radicals.

To further explore the Li-storage behaviors, we mea- sure the EIS (Fig. 8) of the three fresh ZIFs and the cycled CoZn-ZIF has AC amplitude of $5 \mathrm{mV}$ in the frequency of $0.01-10^{6} \mathrm{~Hz}$. For the fresh electrodes, the solution resistances $\left(R_{\mathrm{s}}\right)$ and the charge transfer resistances $\left(R_{\mathrm{ct}}\right)$ are moderate demonstrating well assembling of cells and excellent contact between electrolyte and active materials. Considering the larger $R_{\mathrm{ct}}$ of fresh CoZn-ZIF, we could conclude that the high capacity of CoZn-ZIF does not rely on better connectivity of electrodes, but relies on the high-activity species of CoZn-ZIF. After cycles, the $R_{\mathrm{s}}$ and $R_{\mathrm{ct}}$ of CoZn-ZIF decrease significantly which could be attributed to better wetting of the electrode and improved connectivity boosted by the destruction of large lattices and formation of ultrasmall nano-domains.

Based on the above ex-situ tests, it is reasonable to draw the following conclusion: (1) more Li-ions can be inserted in the CoZn-ZIF structures when compared with Co-ZIF67 and Zn-ZIF-8, which leads to a high reversible capacity of $605.8 \mathrm{~mA} \mathrm{~h} \mathrm{~g}^{-1}$ at a current density of $100 \mathrm{~mA} \mathrm{~g}^{-1}$ for CoZn-ZIF; (2) accompanying with $\mathrm{Li}$ insertion/extraction, most $\mathrm{Co}-\mathrm{N}$ bonds would gradually break/regenerate upon the formation/dissociation process of $\mathrm{Li}-\mathrm{N}$ bonds; (3) the incomplete recoordination of $\mathrm{Co}-\mathrm{N}$ during delithiation would lead to the formation of nitrogen radicals and the collapse of long range order for CoZn-ZIF. It also should be mentioned that a high $\mathrm{N}$ content in ZIF-8 derived porous carbon contributes to a high specific capacity for the adsorbtion of Li by the $\mathrm{N}$ atoms [20]. In this article, to activate the $\mathrm{N}$ atoms for Li storage, bimetallic ZIF was reasonablely designed and the synergistic effect finally makes $\mathrm{N}$ atom to be a reversible lithiation sites.

\section{CONCLUSIONS}

In this work, we synthesized a bimetallic CoZn-ZIF by a simple hydrothermal method. For the synergistic effect of the $\mathrm{Co}^{2+}$ and $\mathrm{Zn}^{2+}$, the CoZn-ZIF displayed a high reversible capacity of $605.8 \mathrm{~mA} \mathrm{~h} \mathrm{~g}^{-1}$ after 100 cycles, which
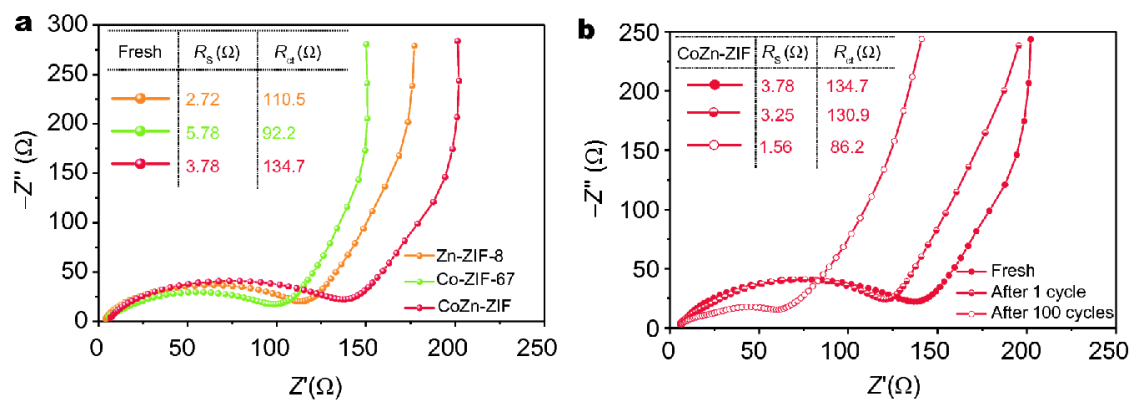

Figure 8 (a) Nyquist plots of the three electrodes at the fresh state. (b) Nyquist plots of the CoZn-ZIF electrodes at fresh state, after 1 cycle and 100 cycles. 
is several times higher than that of monometallic Co-ZIF67 and Zn-ZIF-8, being the best one among ZIFs. Ex-situ studies suggest that the redox participation of nitrogen atoms can involve four more Li into the CoZn-ZIF unit. During the process, Co-N bond could break and recoordinate while $\mathrm{Zn}-\mathrm{N}$ remained unchanged, accompanied by collapse of long range order. This bond breakage/recoordination mechanism may bring about more opportunities for energy-storage application of MOFs.

Received 7 November 2017; accepted 28 December 2017; published online 25 January 2018

1 Armand M, Tarascon JM. Building better batteries. Nature, 2008, 451: 652-657

2 Tarascon JM, Armand M. Issues and challenges facing rechargeable lithium batteries. Nature, 2001, 414: 359-367

3 Zhou HC, Long JR, Yaghi OM. Introduction to metal-organic frameworks. Chem Rev, 2012, 112: 673-674

4 Zhu QL, Xu Q. Metal-organic framework composites. Chem Soc Rev, 2014, 43: 5468-5512

5 Dou Y, Zhou J, Zhou A, et al. Visible-light responsive MOF encapsulation of noble-metal-sensitized semiconductors for highperformance photoelectrochemical water splitting. J Mater Chem A, 2017, 5: 19491-19498

6 Zhou J, Dou Y, Zhou A, et al. MOF template-directed fabrication of hierarchically structured electrocatalysts for efficient oxygen evolution reaction. Adv Energy Mater, 2017, 7: 1602643

7 Gou L, Hao LM, Shi YX, et al. One-pot synthesis of a metalorganic framework as an anode for Li-ion batteries with improved capacity and cycling stability. J Solid State Chem, 2014, 210: 121124

$8 \mathrm{Hu} \mathrm{X}, \mathrm{Hu} \mathrm{H}, \mathrm{Li} \mathrm{C}$, et al. Cobalt-based metal organic framework with superior lithium anodic performance. J Solid State Chem, 2016, 242: 71-76

$9 \mathrm{Hu} \mathrm{H}$, Lou X, Li C, et al. A thermally activated manganese 1,4benzenedicarboxylate metal organic framework with high anodic capability for Li-ion batteries. New J Chem, 2016, 40: 9746-9752

10 Lou X, Hu H, Li C, et al. Capacity control of ferric coordination polymers by zinc nitrate for lithium-ion batteries. RSC Adv, 2016, 6: 86126-86130

11 Jin Y, Zhao C, Sun Z, et al. Facile synthesis of Fe-MOF/RGO and its application as a high performance anode in lithium-ion batteries. RSC Adv, 2016, 6: 30763-30768

12 Maiti S, Pramanik A, Manju U, et al. Reversible lithium storage in manganese 1,3,5-benzenetricarboxylate metal-organic framework with high capacity and rate performance. ACS Appl Mater Interfaces, 2015, 7: 16357-16363

13 Li C, Lou X, Shen M, et al. High anodic performance of Co 1,3,5benzenetricarboxylate coordination polymers for Li-ion battery. ACS Appl Mater Interfaces, 2016, 8: 15352-15360

14 Maiti S, Pramanik A, Manju U, et al. $\mathrm{Cu}_{3}(1,3,5$-benzenetricarboxylate $)_{2}$ metal-organic framework: A promising anode material for lithium-ion battery. Micropor Mesopor Mater, 2016, 226: 353-359

$15 \mathrm{Hu}$ X, Lou X, Li C, et al. Facile synthesis of the Basolite F300-like nanoscale Fe-BTC framework and its lithium storage properties.
RSC Adv, 2016, 6: 114483-114490

$16 \mathrm{Li} \mathrm{T}, \mathrm{Li} \mathrm{C}, \mathrm{Hu} \mathrm{X}$, et al. Reversible lithium storage in manganese and cobalt 1,2,4,5-benzenetetracarboxylate metal-organic framework with high capacity. RSC Adv, 2016, 6: 61319-61324

17 Li C, Hu X, Lou X, et al. The organic-moiety-dominated $\mathrm{Li}^{+}$intercalation/deintercalation mechanism of a cobalt-based metalorganic framework. J Mater Chem A, 2016, 4: 16245-16251

18 Gong T, Lou X, Gao EQ, et al. Pillared-layer metal-organic frameworks for improved lithium-ion storage performance. ACS Appl Mater Interfaces, 2017, 9: 21839-21847

19 Ning Y, Lou X, Li C, et al. Ultrathin cobalt-based metal-organic framework nanosheets with both metal and ligand redox activities for superior lithium storage. Chem Eur J, 2017, 23: 15984-15990

20 Zheng F, Yang Y, Chen Q. High lithium anodic performance of highly nitrogen-doped porous carbon prepared from a metal-organic framework. Nat Commun, 2014, 5: 5261

21 Han Y, Qi P, Li S, et al. A novel anode material derived from organic-coated ZIF-8 nanocomposites with high performance in lithium ion batteries. Chem Commun, 2014, 50: 8057-8060

22 Zhang G, Hou S, Zhang H, et al. High-performance and ultrastable lithium-ion batteries based on MOF-derived ZnO@ZnO quantum dots/C core-shell nanorod arrays on a carbon cloth anode. Adv Mater, 2015, 27: 2400-2405

23 Cheng F, Li WC, Zhu JN, et al. Designed synthesis of nitrogen-rich carbon wrapped Sn nanoparticles hybrid anode via in-situ growth of crystalline ZIF-8 on a binary metal oxide. Nano Energy, 2016, 19: 486-494

24 Mao Y, Li G, Guo Y, et al. Foldable interpenetrated metal-organic frameworks/carbon nanotubes thin film for lithium-sulfur batteries. Nat Commun, 2017, 8: 14628

25 Li Z, Huang X, Sun C, et al. Thin-film electrode based on zeolitic imidazolate frameworks (ZIF-8 and ZIF-67) with ultra-stable performance as a lithium-ion battery anode. J Mater Sci, 2017, 52: 3979-3991

26 Lin Y, Zhang Q, Zhao C, et al. An exceptionally stable functionalized metal-organic framework for lithium storage. Chem Commun, 2015, 51: 697-699

27 Li C, Hu X, Lou X, et al. Bimetallic coordination polymer as a promising anode material for lithium-ion batteries. Chem Commun, 2016, 52: 2035-2038

28 Wu S, Zhu Y, Huo Y, et al. Bimetallic organic frameworks derived $\mathrm{CuNi}$ /carbon nanocomposites as efficient electrocatalysts for oxygen reduction reaction. Sci China Mater, 2017, 60: 654-663

29 An X, Yang H, Wang Y, et al. Hydrothermal synthesis of coherent porous $\mathrm{V}_{2} \mathrm{O}_{3}$ /carbon nanocomposites for high-performance lithium- and sodium-ion batteries. Sci China Mater, 2017, 60: 717727

30 Hachuła B, Nowak M, Kusz J. Crystal and molecular structure analysis of 2-methylimidazole. J Chem Crystlogr, 2010, 40: 201206

31 Zhou K, Mousavi B, Luo Z, et al. Characterization and properties of $\mathrm{Zn} / \mathrm{Co}$ zeolitic imidazolate frameworks vs. ZIF-8 and ZIF-67. J Mater Chem A, 2017, 5: 952-957

32 Kaur G, Rai RK, Tyagi D, et al. Room-temperature synthesis of bimetallic $\mathrm{Co}-\mathrm{Zn}$ based zeolitic imidazolate frameworks in water for enhanced $\mathrm{CO}_{2}$ and $\mathrm{H}_{2}$ uptakes. J Mater Chem A, 2016, 4: 14932-14938

33 Jiang $\mathrm{Y}$, Zhang D, Li Y, et al. Amorphous $\mathrm{Fe}_{2} \mathrm{O}_{3}$ as a high-capacity, high-rate and long-life anode material for lithium ion batteries. Nano Energy, 2014, 4: 23-30 
34

Guo CS, Sun L, Hermann K, et al. X-ray absorption from large molecules at metal surfaces: Theoretical and experimental results for Co-OEP on Ni(100). J Chem Phys, 2012, 137: 194703-194703

Acknowledgements This work was supported by the National Natural Science Foundation of China for Excellent Young Scholars (21522303), the National Natural Science Foundation of China (21373086), the Basic Research Project of Shanghai Science and Technology Committee (14JC1491000), the Large Instruments Open Foundation of East China Normal University, the National Key Basic Research Program of China (2013CB921800) and the National High Technology Research and Development Program of China (2014AA123401). We acknowledge the support from the National Synchrotron Radiation Laboratory (NSRL) for the sXAS experiments. We also thank Dr. Jiahui Yang from Bruker for the support of EPR measurements and analysis.

Author contributions $\mathrm{Hu} B$ proposed and guided the whole project. Lou $\mathrm{X}$ designed the experiment and wrote the manuscript. Ning $\mathrm{Y}$ performed the experiments. Li C polished the manuscript. Hu X helped characterize the materials. Shen $\mathrm{M}$ helped analyze the data. All authors participated in the project discussion and reviewed the manuscript.

Conflict of interest The authors declare no conflict of interest.

Supplementary Information Supplementary data are available in the online version of the paper.

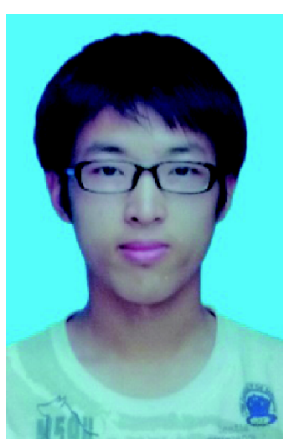

Xiaobing Lou is a PhD student at the East China Normal University. His research interests are design of metal organic frameworks and their electrochemical application, with a specific focus on the mechanism research by means of magnetic resonance technique.

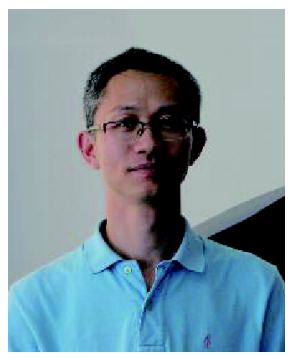

Bingwen Hu received his PhD degree in 2009 from the National High field NMR Center, Université Lille 1, France. After that, he returned to the East China Normal University and started his career as a research scientist. Now, he is a professor scientist at Shanghai Key Laboratory of Magnetic Resonance and adjunct professor at the State Key Laboratory of Precision Spectroscopy at the East China Normal University. His research interests include new method development in solid state NMR, and the application of NMR and EPR for batteries. He has published more than one hundred papers in refereed journals.

\section{基于氮原子氧化还原的双金属沸石咪唑框架用于高性能锂离子电池负极}

娄霄冰, 宁艳群, 李超, 胡小诗, 沈明, 胡炳文 ${ }^{*}$

摘要 本文首次水热合成了一种双金属沸石咪唑有机框架(CoZn-ZIF)并将其用于锂离子电池负极. 该材料在以 $100 \mathrm{~mA} \mathrm{~g}$ 青电流充放电时, 具有 $605.8 \mathrm{~mA} \mathrm{~h} \mathrm{~g}$ 的可逆容量, 远远大于同类单金属材料(Co-ZIF-67和Zn-ZIF-8). 为了探知该高容量来源, 我们进行了一系列非原位实 验, 包括同步辐射软线、粉末衍射、透射电镜以及顺磁共振. 研究表明该双金属高容量主要得益于配位氮原子参与锂化反应, 在这一过程 中还伴随了金属氮配位键的打开与重新配合. 另外, 少量金属氮配位键的不可逆反应会导致该材料晶体的无序化以及一些氮自由基的生 成. 这种高活性双金属的设计思路和反应机理可推广到包括催化、气体吸附等的其他应用中. 